\title{
Supporting Information \\ A novel organically templated zinc phosphite synthesized in phosphorous acid flux and its hydrothermal analogue
}

Zhi-En Lin, Wei Fan, Feifei Gao, Naotaka Chino, Toshiyuki Yokoi and Tatsuya Okubo*

Department of Chemical System Engineering, The University of Tokyo, 7-3-1 Hongo, Bunkyo-ku, Tokyo 113-8656, Japan. Fax: +8135800 3806; Tel: +81 35841 7348;

E-mail: okubo@chemsys.t.u-tokyo.ac.jp

Figure S1. ORTEP view of the asymmetric unit of 1, showing the labeling scheme and the $30 \%$ probability displacement ellipsoids. Atom labels have "A" refer to symmetry-generated atoms.

Figure S2. Space-filling presentation of the supramolecular bbp chain in $\mathbf{1}$ (color code: $\mathrm{C}$, gray; $\mathrm{N}$, blue).

Figure S3. ORTEP view of the asymmetric unit of $\mathbf{2}$, showing the labeling scheme and the $30 \%$ probability displacement ellipsoids. Atom labels have "A" refer to symmetry-generated atoms.

Figure S4. The stacking of the layers of 2 viewed along the [010] direction. Color code: $\mathrm{ZnO}_{3} \mathrm{~N}$ tetrahedra, yellow; $\mathrm{HPO}_{3}$ pseudo pyramids, green.

Figure S5. IR spectra of 1 and 2.

Figure S6. Simulated and experimental powder X-ray diffraction patterns of $\mathbf{1}$ synthesized by the use of $\mathrm{Zn}(\mathrm{OAc})_{2} \cdot 2 \mathrm{H}_{2} \mathrm{O}$ as the zinc source.

Figure S7. Simulated and experimental powder X-ray diffraction patterns of $\mathbf{1}$ synthesized by the use of $\mathrm{ZnO}$ as the zinc source.

Figure S8. Simulated and experimental powder X-ray diffraction patterns of 2.

Figure S9. Simulated and experimental powder X-ray diffraction patterns of $\left(\mathrm{C}_{2} \mathrm{~N}_{2} \mathrm{H}_{10}\right) \mathrm{Zn}_{2}\left(\mathrm{HPO}_{3}\right)_{3}$.

Figure S10. TGA curve of 1.

Figure S11. TGA curve of 2.

Figure S12. IR spectrum of $\mathrm{H}_{2} \mathrm{bbp} \cdot \mathrm{Zn}_{3}\left(\mathrm{HPO}_{3}\right)_{4}$.

Figure S13. XRD pattern of $\mathrm{H}_{2} \mathrm{bbp} \cdot \mathrm{Zn}_{3}\left(\mathrm{HPO}_{3}\right)_{4}$. 


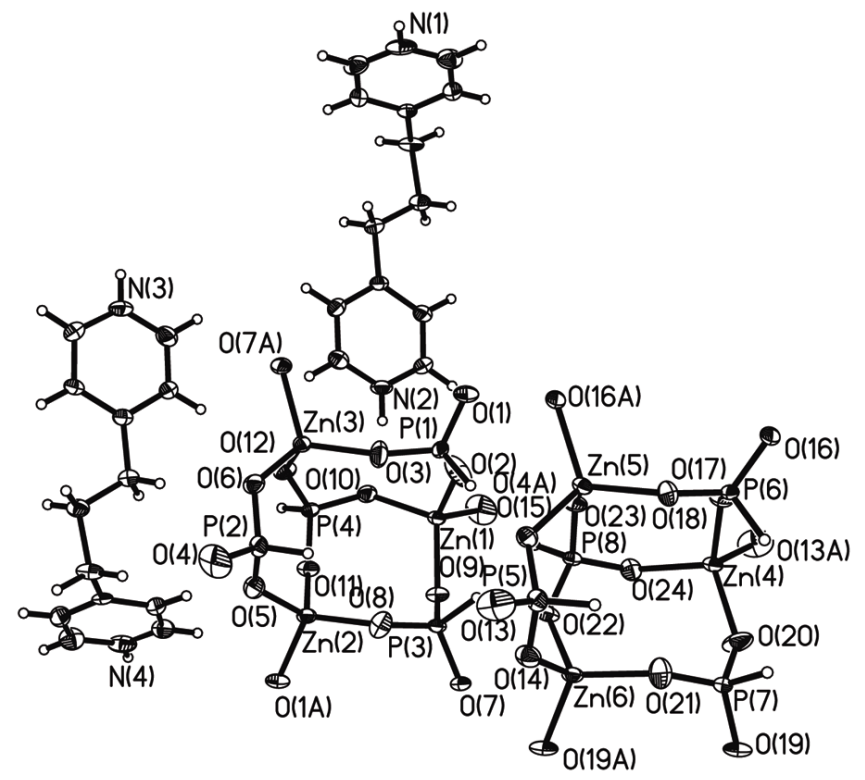

Figure S1

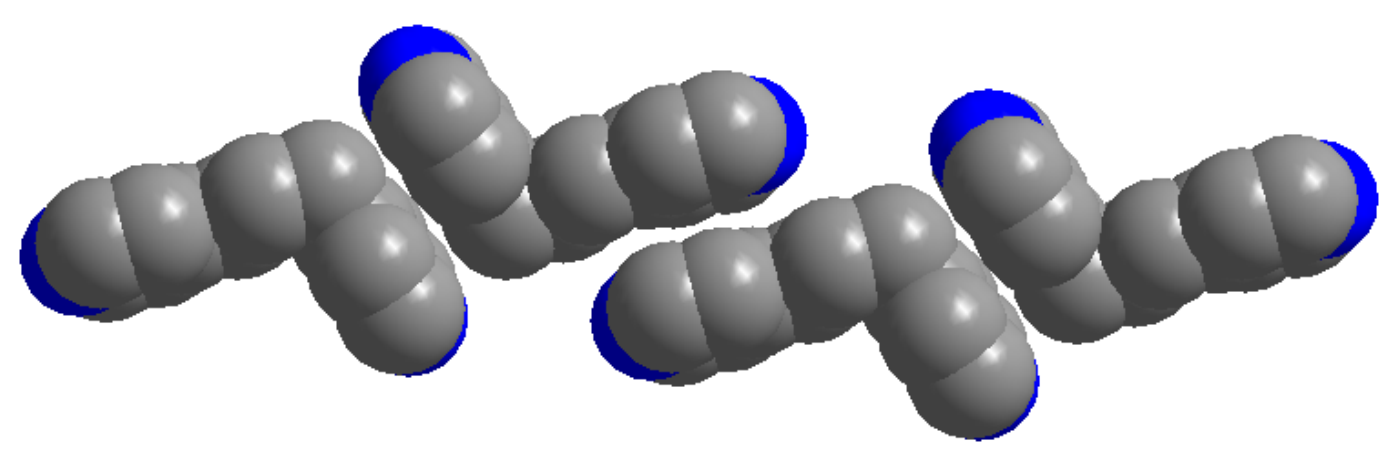

Figure S2 


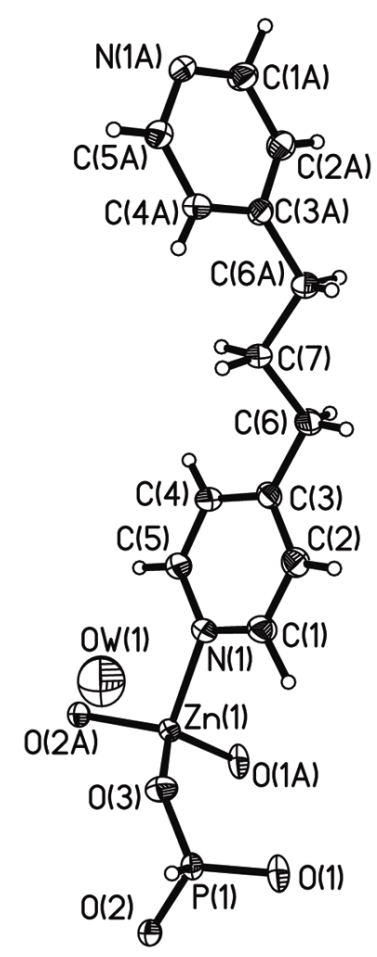

Figure S3

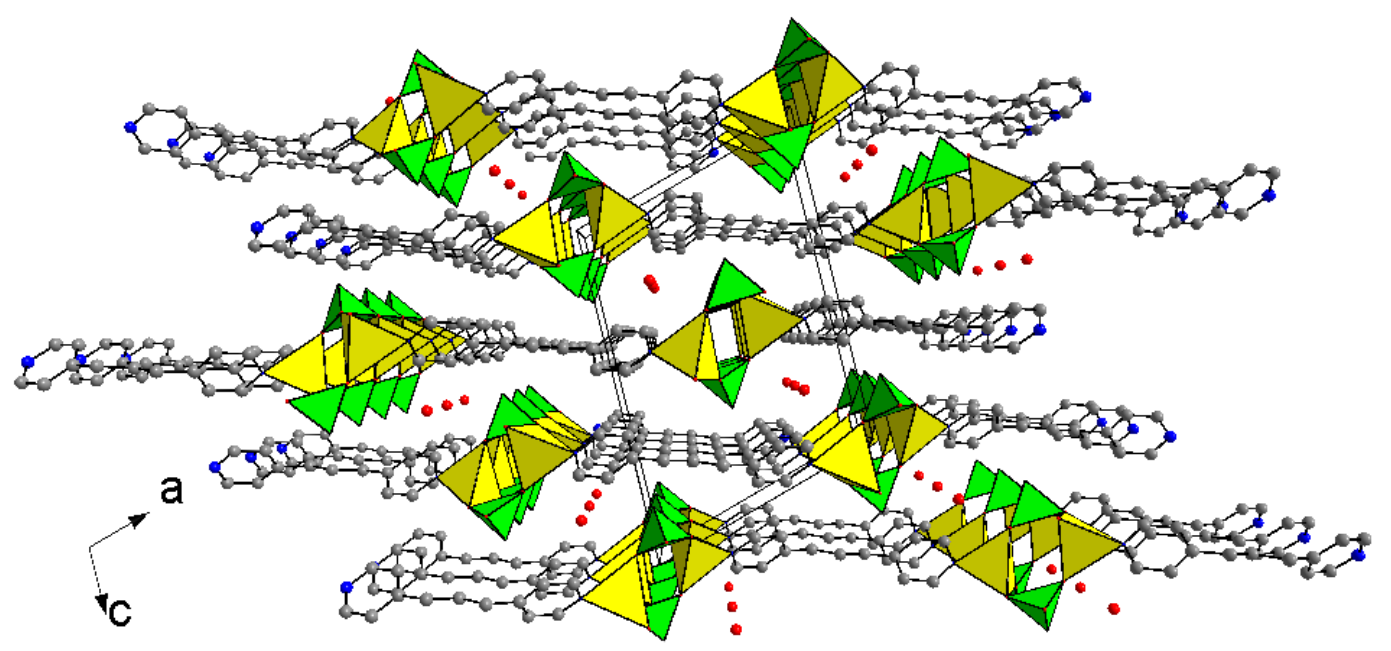

Figure S4 


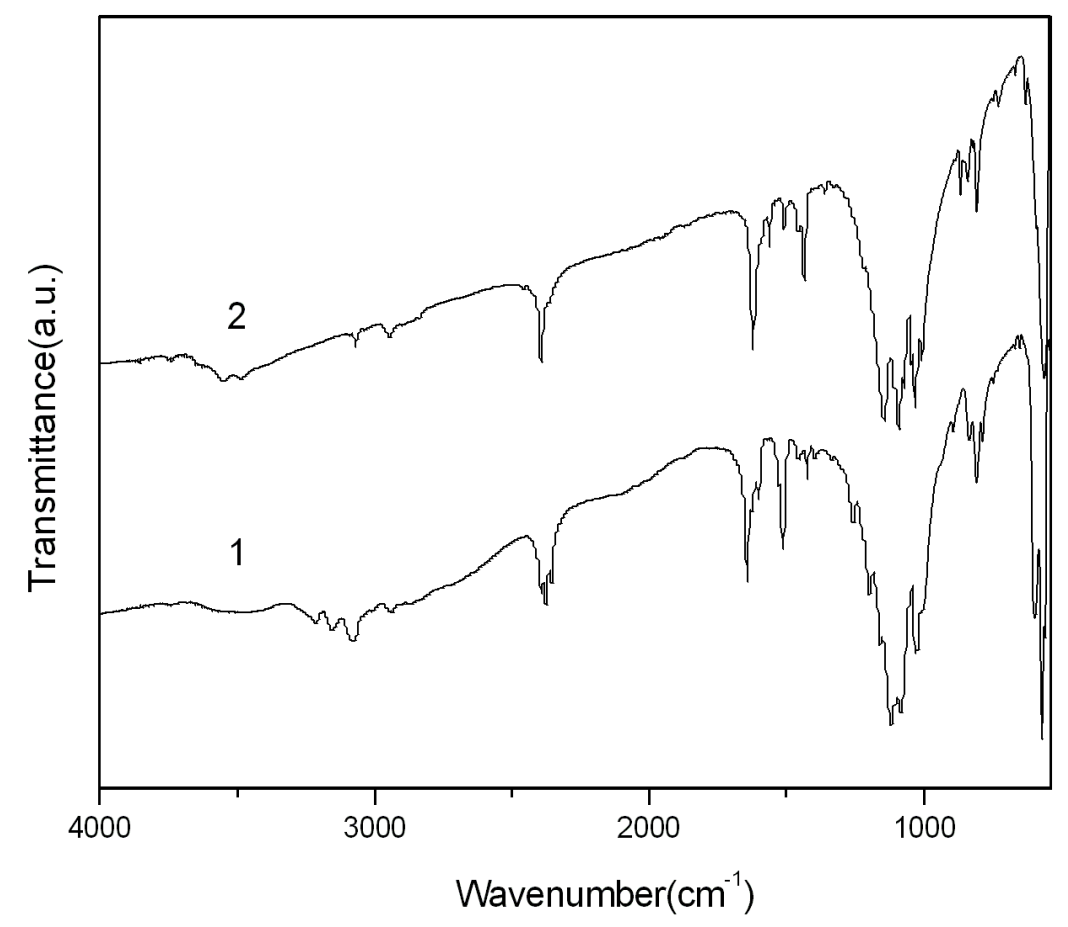

Figure S5

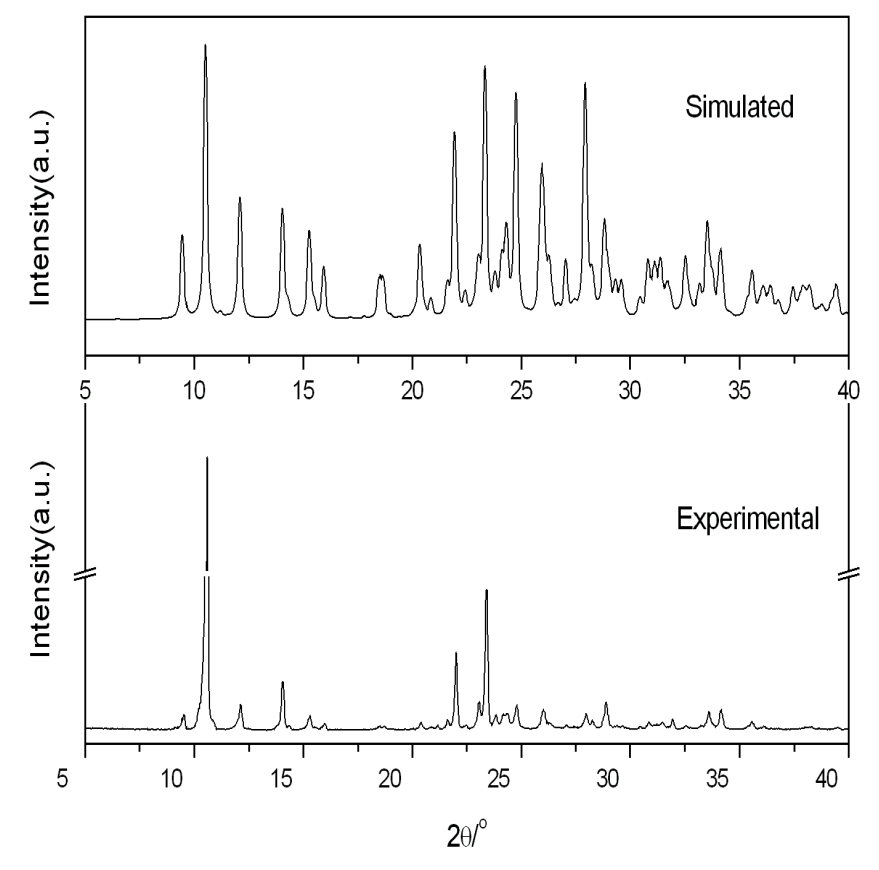

Figure S6 


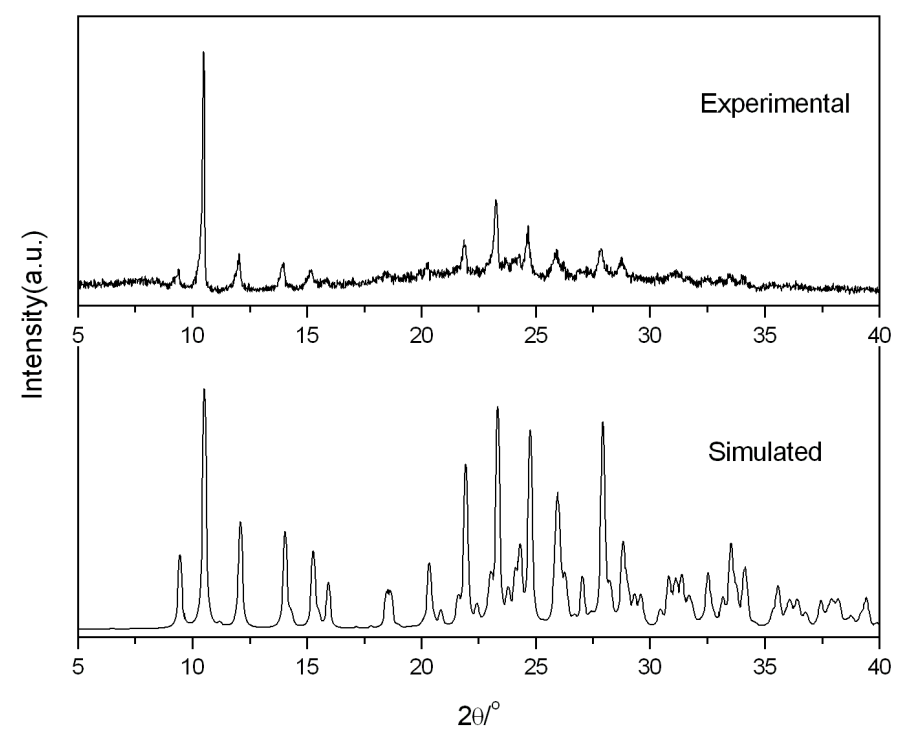

Figure S7

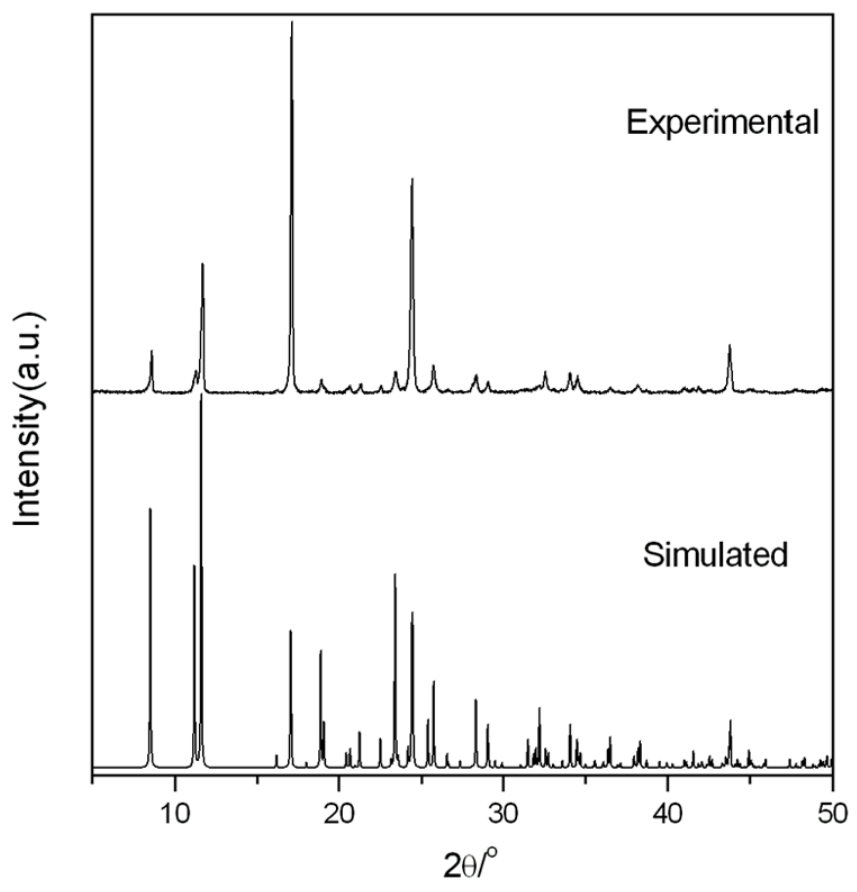

Figure S8 


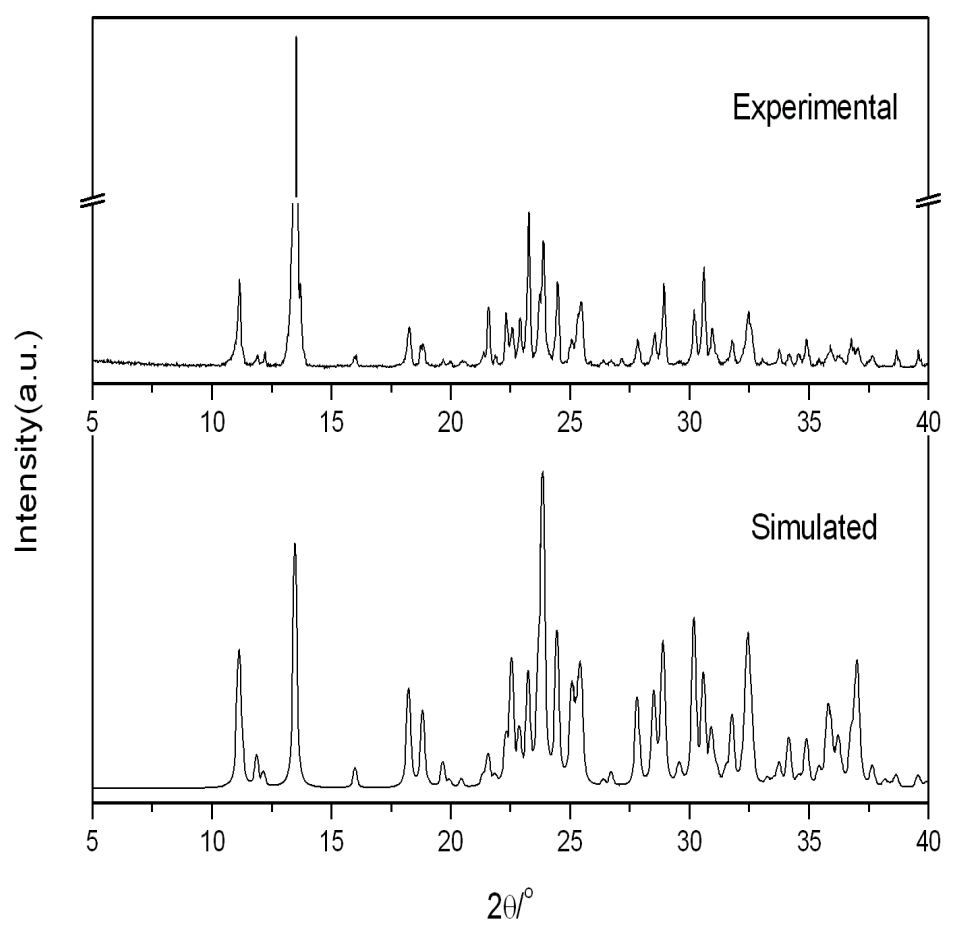

Figure S9

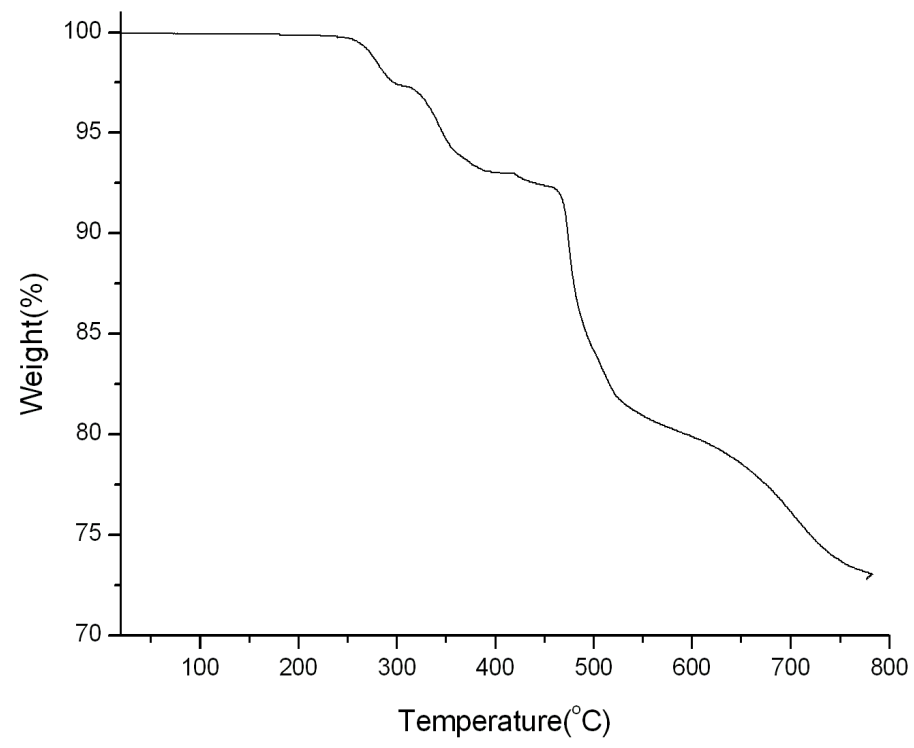

Figure S10 


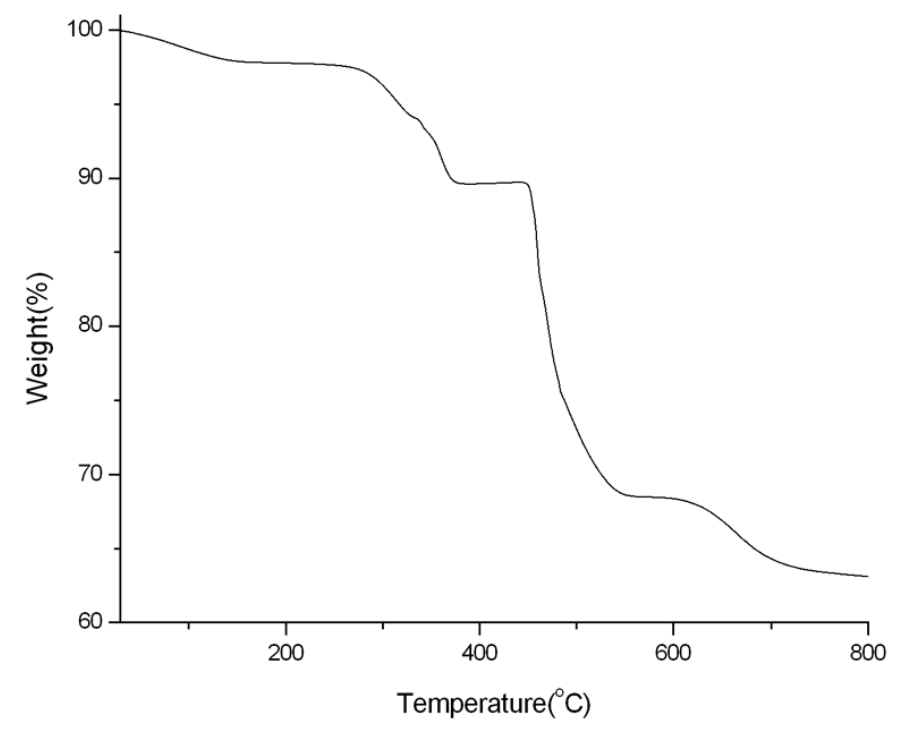

Figure S11

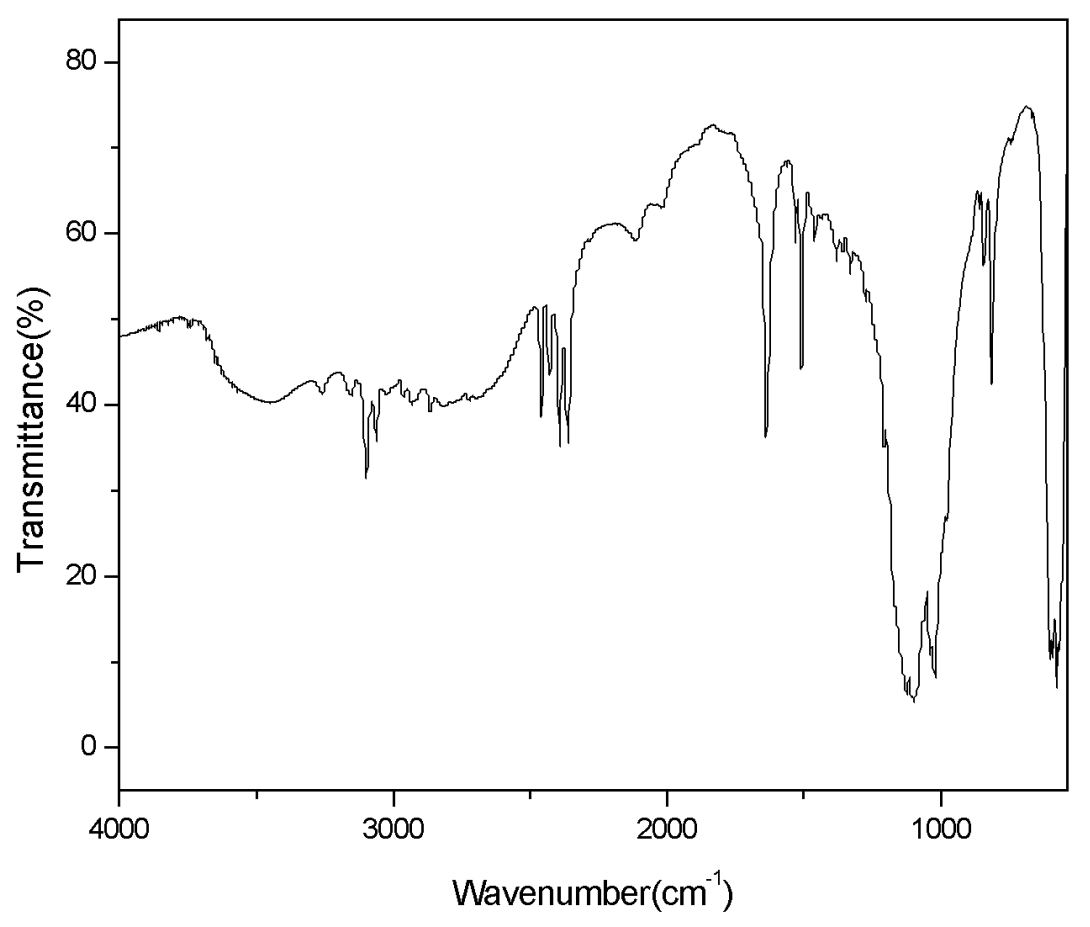

Figure S12 


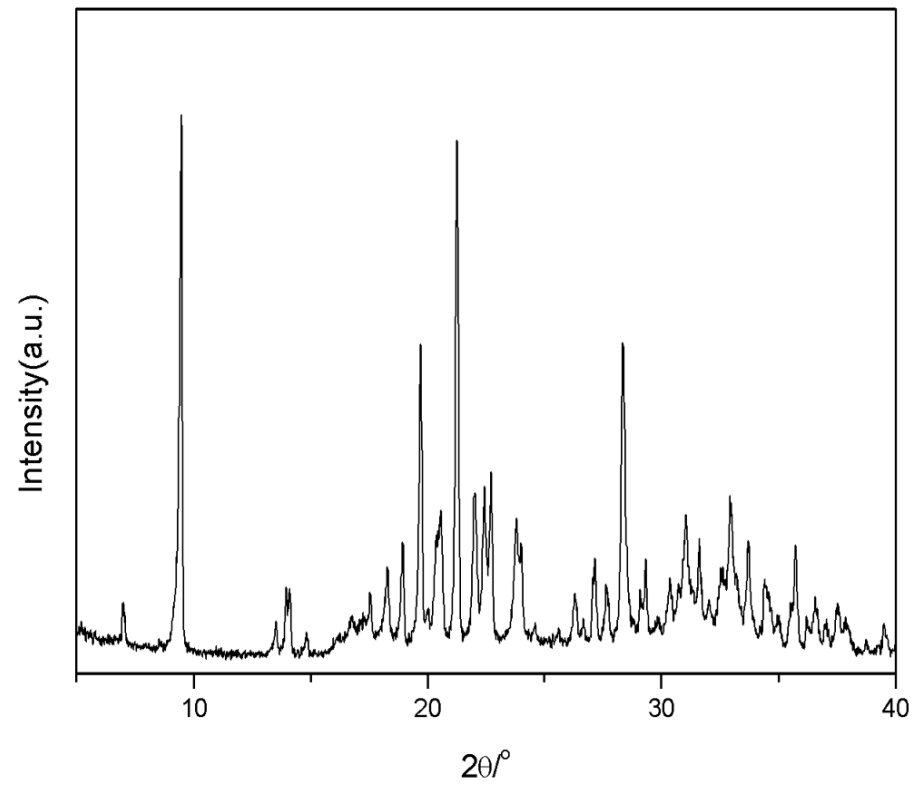

Figure S13 